\title{
Evaluation of Liquid Film Thickness in Gas-Liquid Annular Flow in Horizontal Pipes Using Three Methods
}

\section{Osokogwu Uche}

Oil \& Gas Engineering Centre, Cranfield University, Bedfordshire, UK

\section{Email address:}

Oxgoodlt@yahoo.com

\section{To cite this article:}

Osokogwu Uche. Evaluation of Liquid Film Thickness in Gas-Liquid Annular Flow in Horizontal Pipes Using Three Methods. International Journal of Energy and Environmental Science. Vol. 5, No. 4, 2020, pp. 57-65. doi: 10.11648/j.ijees.20200504.11

Received: March 4, 2020; Accepted: March 23, 2020; Published: September 3, 2020

\begin{abstract}
Experimental investigations on annular flow film thickness were conducted using a closed-loop horizontal pipe with an internal diameter of 2-inch $(0.0504 \mathrm{~m})$. The aim is to progress the understanding of such flow and facilitate the optimum design of hydrocarbon production systems were such flow is encountered. Liquid film thickness was extensively investigated using three methods: the conductance probe sensors installed at the bottom of the pipe, conductivity ring sensors and triangular relationship model. From these methods, liquid film thickness was proven to decrease with increase in superficial gas velocity, while increases with increase in superficial liquid velocity. In comparison, the predicted triangular relationship liquid film thickness matched better with the liquid film thickness obtained from conductance probe sensors at all the flow conditions in the experiments, while the conductivity ring sensor results matched closely at superficial liquid velocity of $0.0505 \mathrm{~m} / \mathrm{s}$ and $0.0714 \mathrm{~m} / \mathrm{s}$ but overestimated at superficial liquid velocity of $0.0903 \mathrm{~m} / \mathrm{s}$ and $0.1851 \mathrm{~m} / \mathrm{s}$. This has shown the impact of high superficial gas velocity on conductivity ring sensors in accounting for liquid film thickness.
\end{abstract}

Keywords: Film Thickness, Gas Velocity, Annular Flow, Sensors, Liquid Entrainment, Flow Rate

\section{Introduction}

Multiphase flow in pipes involve different phases flowing together, either at the same or different velocity. As the flow develops along vertical or horizontal pipes, different flow patterns or flow regimes could be observed, depending on the dominant phase in the system, properties of each phase in the flow (e.g. viscosity, density) its velocity and pipe geometry. The focus here is on annular flow, which is a complex flow regime encountered in horizontal and vertical pipes in the oil and gas industry, [14]. Gas-liquid annular flow is also encountered in nuclear power plants, chemical and refining processes like reactors, heat exchangers.

Annular flow in horizontal pipes flow with much gas velocity at the core centre of the pipe with impact of gravity leaving the circumferential liquid film on the internal walls of the pipe which drains to the bottom of the pipe as film thickness,[15]. According to [19], the liquid flows as a film along the pipe walls under gravity, induced by the high velocity gas stream in the pipe core. The gas together with entrained liquid droplets, flows within the core of the pipe; at high velocity the entrained droplets travel at a velocity close to that of the gas, [8]. Annular flow represents a thick liquid film at the bottom that moves slowly on the internal pipe walls than the gas phase, [8]. The combined slow flow of the liquid at the bottom with the fast gas phase at the interface, aids to increase the pressure gradient and wall shear stress in annular flow. However, a thin liquid film exists at the curved surfaces and the upper walls while a thick liquid film exists at the bottom of the internal diameter of horizontal pipes, [14]. More so, the liquid which is non-uniform flows circumferentially around the pipe walls. According to [20], the asymmetry distribution of annular flow in horizontal pipes is dependent on the mass flow rate of the liquid and gas. Liquid film thickness is observed to be higher at the bottom of the pipe compared to the curved surface area and the upper walls of the pipe internally. This is because of the effects of gravity-induced drainage, which increases the liquid film thickness at the bottom of the pipe, [20, 21]. Also, [13] investigated and reported on circumferential water film thickness in annular in pipes, [1] presented film thickness at the upper part of the walls of the pipe while [2] conducted experiments on film thickness with respect to axial flow. [3, $22,9,18]$ likewise investigated liquid film thickness in 
annular flow in pipes.

In determining liquid film thickness in the pipes, the fraction of liquid droplets dispersed in the gas core are accounted while the film thickness at the walls of the pipes is measured using any of the following techniques: optical techniques: e.g. pin, high speed cameras/Laser for detecting interface, electrical techniques: capacitance, conductance method (flush-mounted, parallel-wire), acoustic techniques: e.g. ultrasonic in which the reflected signals of time interval emitted from gas-liquid interface are converted to film thickness, and the radiological techniques: e.g. X-ray, neutrons and gamma-ray. The radiological techniques use different attenuations to measure liquid film thickness in the pipes. The above techniques differ in measurement principles, ease of use, frequency response, calibration techniques, accuracy and method of installation (intrusive or non-intrusively mounted) and ease of data extractions/analysis.

For the liquid droplets dispersed in the gas core, it involves a droplet-breakup from the liquid film due to wave actions of the high gas velocity flow in the pipes. Entrainments in gas core have been investigated with wide publications. Among the experimental investigations on entrainment in horizontal pipes are: [23] who presented an entrainment correlation group $R$ ( $\mathrm{Ibmft}^{3} / \mathrm{Ibf}-\mathrm{hr}$ ) which was developed based on pipe internal diameters of $25.4 \mathrm{~mm}$ and $76.2 \mathrm{~mm}$ with superficial liquid velocities of $0.12-0.77 \mathrm{~m} / \mathrm{s}$ and superficial gas velocities of $12-62 \mathrm{~m} / \mathrm{s}$. Again, critical Weber number ranging from 13 to 22 and pressure gradient, were considered in the correlation expressed as:

$$
R=\left(\frac{q_{l}}{q_{g}}\right)\left(\frac{N_{W e c r} W_{L E}}{(d p / d l)_{G}}\right)
$$

The above equation (1) of the entrainment correlation group $R$ could be re-written with Lockhart-Martinelli parameter $\mathrm{X}$, if the correlation group $R$ is within the ranges of 0.5 to 200 .

$$
R=168 X^{2.05}
$$

while,

$$
X=\sqrt{\frac{(d p / d l)_{L}}{(d p / d l)_{G}}}
$$

Correlation on gas velocity, viscosity, droplet concentration, surface tension and liquid density was presented by [16]. The correlation is expressed as:

$$
F_{E}=0.015+0.44 \log \left[\frac{\rho_{m}}{\rho_{L}}\left(\frac{\mu_{L V_{g}^{2}}}{\sigma}\right) 10^{4}\right]
$$

More so, [5], developed their correlation based on air/water flow using a $0.0231 \mathrm{~m}$ pipe diameter. The flow conditions considered in their correlation were based on Vsg of $15-88 \mathrm{~m} / \mathrm{s}$, Vsl of $0.0072-0.9 \mathrm{~m} / \mathrm{s}$, gas density (between 1.6 to $2.75 \mathrm{~kg} / \mathrm{m}^{3}$ ), liquid density of $1000 \mathrm{~kg} / \mathrm{m} 3$ with liquid viscosity of $1 \mathrm{mPas}$ and surface tension of $73 \mathrm{mN} / \mathrm{m}$. The developed correlation is

$$
\dot{\varepsilon}=K_{A}\left(\frac{W_{L F}-W_{L F c}}{P}\right) V_{g}^{2} \rho_{g}^{0.5} \rho_{f}^{0.5}
$$

where,

$$
K_{A}=3.5 \times 10^{-6} \frac{\sec ^{2}}{\mathrm{~kg}}
$$

and;

$$
\frac{W_{L F c}}{P}=0.046, \frac{\mathrm{kg}}{\mathrm{m} \cdot \mathrm{s}}
$$

The correlation considered a pipe with an internal diameter of $0.0231 \mathrm{~m}$.

An explicit correlation that considers critical liquid film rate was reported by [17]. The correlation considers deposition coefficient, droplet size, entrainment fraction, maximum entrainment as noted by $[12,10]$. Below is the correlation:

$$
\frac{f_{E} / f_{E m}}{1-^{f_{E}} / f_{E m}}=9 \times 10^{-8}\left(\frac{D v_{g \sqrt{\rho_{L}-\rho_{g}}}^{3}}{\sigma v d}\right)
$$

where,

$$
f_{E m}=1-\frac{W_{F c r}}{W_{L}}
$$

Where critical liquid-film-flow rate could be calculated using:

$$
W_{F c r}=0.25 \mu_{L} \pi D R_{e F c r}
$$

While the Reynolds number for liquid-film-flow rate is:

$$
R_{e F c r}=7.3(\log \omega)^{3}+44.2(\log \omega)^{2}-263 \log \omega+439(11)
$$

and,

$$
\omega=\left(\frac{\mu_{l}}{\mu_{g}}\right) \sqrt{\frac{\rho_{g}}{\rho_{l}}}
$$

The limitation of this correlation is that, critical-film-flow rate gives a negative result on maximum fraction of entrainment for low liquid flow rates.

Also, [12] developed correlations for entrainment fraction and maximum entrainment based on pipe diameters of $50.8 \mathrm{~mm}$ and $152.4 \mathrm{~mm}$ (ID). In the developed correlations, superficial liquid and gas velocities, pipe diameter, liquid wave, deposition coefficient and wave fraction were considered. The entrainment fraction correlation is as follows:

$$
f_{E}=\frac{1-\frac{4}{V_{S L} \pi D^{2}} \int_{0}^{A\left(A_{L h}\right)} u d A}{1+\frac{K g}{V_{S G}} \frac{4 S_{I} L_{W}}{\emptyset \pi D^{2}}}
$$

while the maximum entrainment correlation is here below:

$$
f_{E m}=1-\frac{q_{F c r}}{q_{L}}
$$

where the critical liquid film flow rate is given as:

$$
q_{f c r}=\pi \mathrm{Dv}\left(12.514+5 h_{L m}^{+} I n h_{L m}^{+}-8.05 h_{L m}^{+}\right)
$$


Where the dimensionless liquid film thickness at maximum entrainment condition is:

$$
h_{L m}^{+}=0.6 R_{e S L}^{0.45}
$$

The correlations could be improved by introducing frequency, wave celerity, amplitude and spacing [12].

The combination of the entrainment correlation results and the reference film thickness from the conductance probes and conductivity ring sensors' experiments, will yield liquid film thickness in annular flow in pipes. However, the emphasis on this paper is to compare the conductance probes, ring sensors and the triangular relationship in harnessing annular flow liquid film thickness in horizontal pipes.

\section{Material and Methodology}

The method involved air/water experiments using a closed loop system pipe of 2-inch $(0.0504 \mathrm{~m}, \mathrm{ID})$ with a total length of $28.68 \mathrm{~m}$. The liquid film thickness was measured using electrical techniques: conductance method (probes) (flushmounted) and conductivity ring sensors with the experimental properties and ranges as:

Table 1. Experimental Properties and Ranges Used.

\begin{tabular}{|c|c|c|}
\hline Properties & Range & Units \\
\hline Temperature & $16.5-19.3$ & ${ }^{\circ} \mathrm{C}$ \\
\hline Pipe internal diameter (flow loop) & 0.0504 & $\mathrm{~m}$ \\
\hline Air flow line internal diameter & 0.0504 & $\mathrm{~m}$ \\
\hline Superficial liquid velocity & $0.0501-0.2001$ & $\mathrm{~m} / \mathrm{s}$ \\
\hline Superficial gas velocity & $8.0774-23.7260$ & $\mathrm{~m} / \mathrm{s}$ \\
\hline
\end{tabular}

The annular flow liquid film thickness results which were obtained using the conductivity ring sensors and conductance probe sensors, were compared with the triangular relationship results.

\section{Experimental Set-Up}

The experiments were conducted using a pipe with an internal diameter of 2-inch $(0.0504 \mathrm{~m})$ at the Process Systems Engineering (PSE) Laboratory, Cranfield University. The 2inch $(0.0504 \mathrm{~m})$ pipeline test facility of $28.68 \mathrm{~m}$ was a closedloop system, where water inlet pipe was connected to the water tank and the outlet was also connected back to the same storage water tank. On the flow loop were, 2 pairs of pressure transducers (Druck) with the upstream (T1) as (PMP 4070, S/N 2642126) and downstream (T2) as (PMP 4070, $\mathrm{S} / \mathrm{N} 2630077$ ) which were installed at $2.08 \mathrm{~m}$ apart from one another. The essence of the difference was to observe the pressure behave immediately after the gas and sand entry points and the multiphase flow behavior after symmetrically distribution of the fluids in the experiments. Other instruments installed were: light emission diode infrared sensor (LED), conductivity ring sensors of double pairs installed at $0.07 \mathrm{~m}$ apart and two set of conductance probes also installed at $0.20 \mathrm{~m}$ apart on the flow loop as shown in Figure 1. The air-line which was a 2-inch $(0.0504 \mathrm{~m})$ has a delivery capacity of superficial gas velocity of $30 \mathrm{~m} / \mathrm{s}$ with air flowmeter, pressure transducers and temperature sensors also connected to it. The sand injection point to the sand sampling location (point) was $5.27 \mathrm{~m}$, while the sand injection point to the upstream conductance probe $(\mathrm{S} 1)$ was $2.39 \mathrm{~m}$ and to second probe downstream (S2) was $2.59 \mathrm{~m}$.

During the experiments, the water line is often open to flow to stabilize before the gas line through the second valve before the vortex air flowmeter. The air supplies were meter and the pressure similarly recorded with $\mathrm{Pg}$ while the temperature, also recorded as T1. These instruments were, connected to a LabVIEW where the data were recorded.
From Figure 1, is the sketch of the 2-inch $(0.0504 \mathrm{~m})$ pipe flow loop, with the instruments/lines representing the colors follows: The Red Line: is for gas supply, the Blue Line: is for water supply, the Pink Line: represents the multiphase flow, while the Green Line: is for sand/water mixture (slurry flow) from the sand hopper.

\section{Mechanism of Sensors used for Film Thickness.}

The two sensors used in the determining liquid film thickness are conductance probe sensors (C1 and $\mathrm{C} 2)$ and conductivity ring sensors S1 and S2 shown in figure 1.

Conductivity Ring Sensors.

The sensors were two pairs of ring-type sensors that were installed on the outer walls of the 2-inch Plexiglas pipe used. They are used to obtain flow values by injecting electric current into the pipes through the outer pair of electrodes and measuring the corresponding electric potential drop in between each successive electrode [4]. The conductivity ring sensors are used to measure liquid hold up. It measures a resistance based on amount of liquid fraction in the system or pipes and gives an output voltage as its readings. In this study, the rings were equally used for liquid film thickness during the experiments.

\section{Conductivity Probe Sensors}

The conductance probe sensors operate based on the conductivity charge caused by conductivity liquid. The sensors when in contact with water, has a potential difference applied to the electrodes. The probe sensors are flush mounted conductance probe sensors consist of two pairs of S1 and S2 which were installed at $0.21 \mathrm{~m}$ apart on the flow loop as shown in Figure 1. They have a circular conductive plate at the center with a diameter of $10.25 \mathrm{~mm}$ as well as an outer circular conductive plate of $1.80 \mathrm{~mm}$ which were duly separated by a $2.40 \mathrm{~mm}$ circular insulator (see Figure 3 ). The conductance probe sensors, detect liquid film thickness by recording the output voltage in a digital data acquisition system (LabVIEW). 


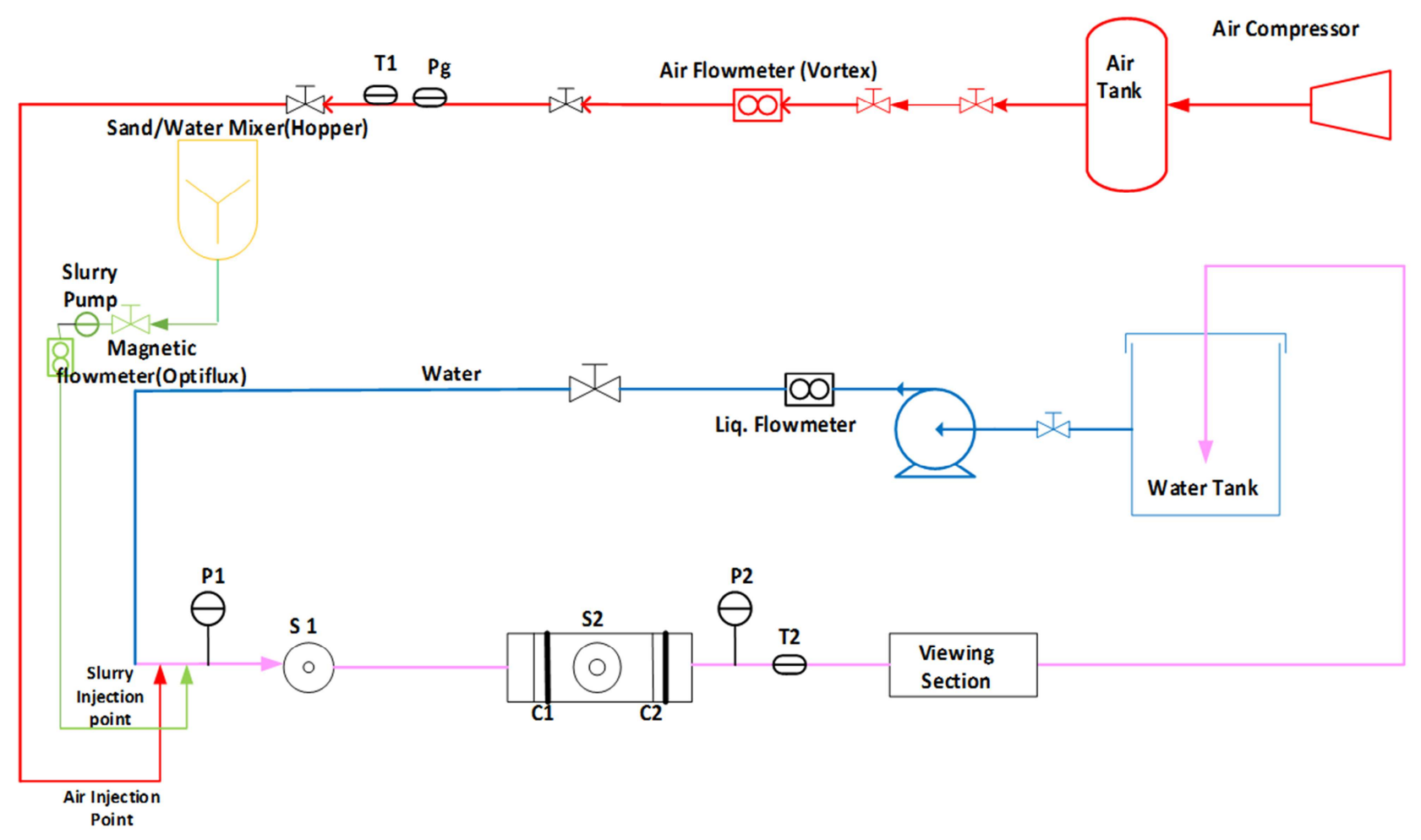

Figure 1. A Sketch of Experimental 2-inch Flow Loop Facility used.

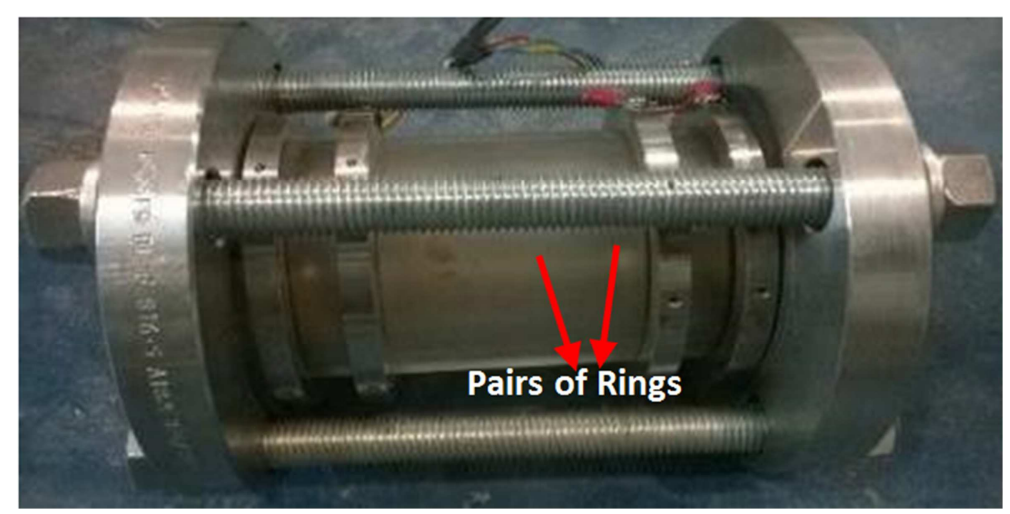

Figure 2. A Typical example of Ring Sensors used.
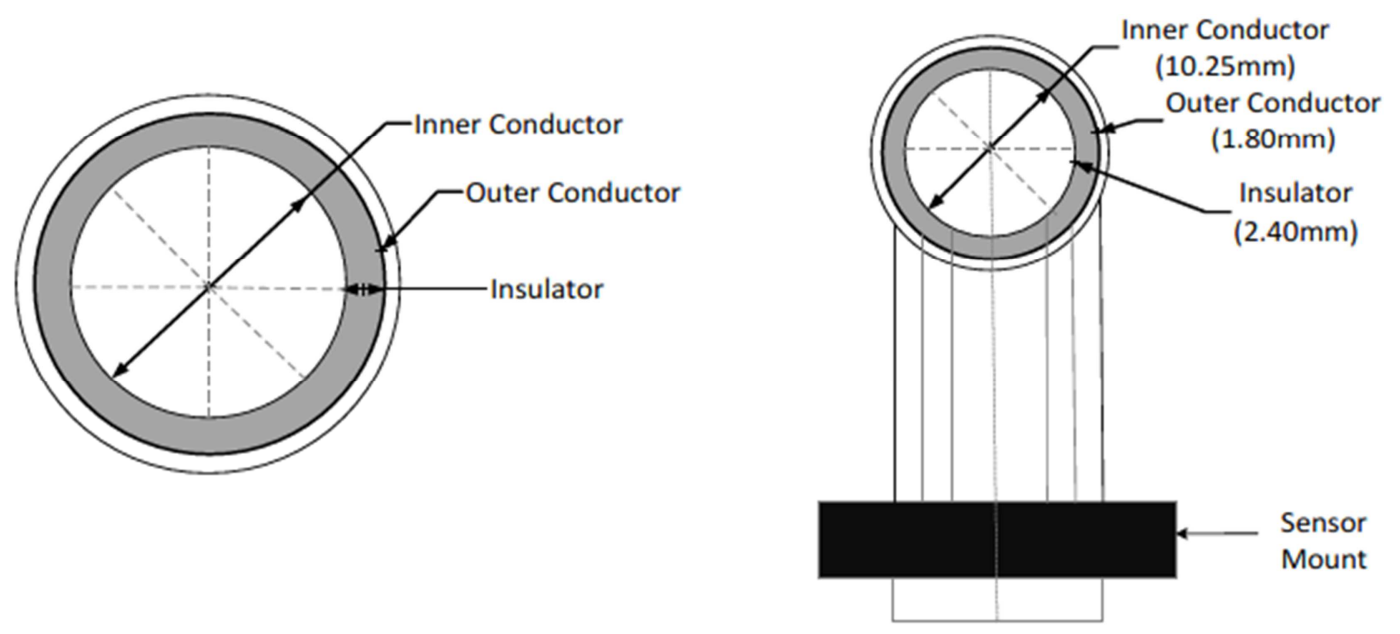

Figure 3. A Sketch of the Sand Probe Sensors Used. 
Procedures for determining Film Thickness.

To produce annular flow trend in the experiments, where the superficial gas velocity will be dominant at the core centre of the pipe, bench calibrations were involved. The annular flow bench calibrations were conducted using conductance probe and conductivity ring sensors in a $50 \mathrm{~mm}$ $(0.0504 \mathrm{~m}, \mathrm{I} . \mathrm{D})$ pipe with a length of $170 \mathrm{~mm}$. The annular flow bench calibrations were achieved, using five solid cylindrical blocks (plastics) of $49 \mathrm{~mm}, 48 \mathrm{~mm}, 47 \mathrm{~mm}, 46 \mathrm{~mm}$ and $45 \mathrm{~mm}$ which were inserted at different times with their voltage recorded. From the bench calibrations, equation (17) was obtained for determining the liquid film thickness as:

$$
\mathrm{Y}=-0.0044 X^{2}+01256 X+0.112
$$

\section{Result and Discussion}

Figure 4, presents the liquid film thickness results. More so, the graph of Figure 4, shows that the liquid film thickness, decreases with increase in superficial gas velocity, and increases with increase in superficial liquid velocity, as average superficial liquid velocity of $0.0505 \mathrm{~m} / \mathrm{s}$ plot indeed, has the lowest film thickness while the superficial liquid velocity of $0.1851 \mathrm{~m} / \mathrm{s}$ represented the highest film thickness. Again, Figure 4 had also shown that, as the superficial liquid velocity becomes higher, the rate of decrease in film thickness becomes insignificant at the bottom of the pipes. This is because of gravity impact overtime on the break-up droplets. As more of the break-up droplets are lifted, they indeed become heavier and with the impact of gravity, drains to the bottom of the pipes. These mechanisms were also noted by $[20,21]$. And for these reasons, the graph of superficial liquid velocity of $0.1851 \mathrm{~m} / \mathrm{s}$ in Figure 4 seems to be a straight line with equal heights across all the superficial gas velocity conditions. However, the heights were not precisely equal as the detailed analyzed results provided in Tables 2-6 proved it.

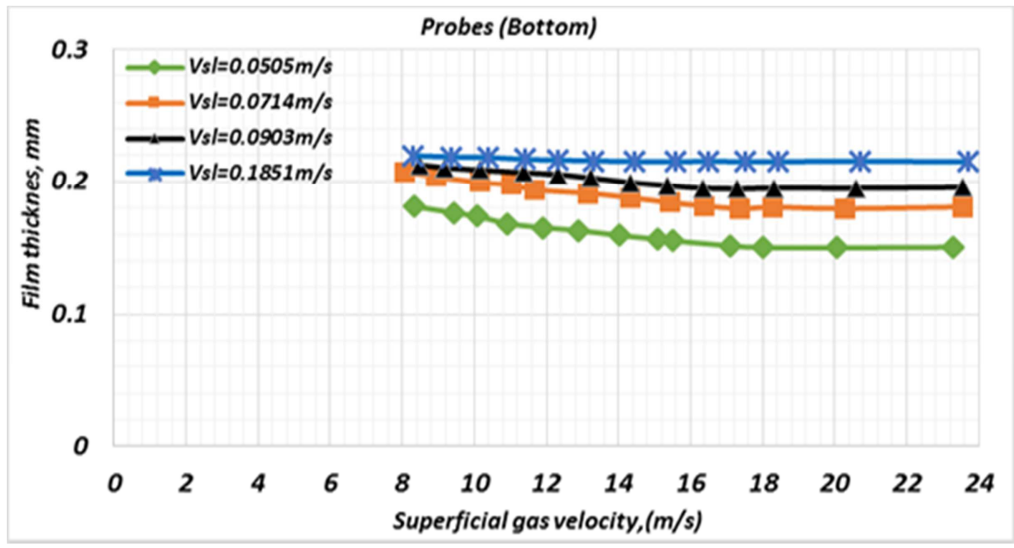

Figure 4. Film thickness (probe at bottom) against superficial gas velocity.

Tables 2-6 are the experimental results of liquid film thickness from conductivity ring sensors, conductance probe sensors and the triangular relationship. The liquid hold-up was obtained from the conductivity ring sensors in the experiments. On liquid entrainment, three correlations namely; [17, 16] and [11] were accessed but [17] was used. The liquid entrainment results were added to both the liquid film thickness results from conductivity ring and conductance probe sensors as shown in Tables 2-6.

Table 2. Experimental Results for Vsl=0.0505m/s with Liquid Entrainment Correlations.

\begin{tabular}{|c|c|c|c|c|c|c|}
\hline \multirow[b]{3}{*}{$\begin{array}{l}\text { HL+Liq } \\
\text { Entrain }\end{array}$} & \multirow{3}{*}{$\begin{array}{l}\text { Rings+ Liq } \\
\text { Entrain } \\
\begin{array}{l}\text { Film Thickness } \\
(\mathrm{mm})\end{array} \\
\end{array}$} & \multirow{3}{*}{$\begin{array}{l}\text { Probes (Bottom) } \\
\text { Film Thickness } \\
(\mathrm{mm})\end{array}$} & \multicolumn{4}{|l|}{$V s \mathrm{l}=0.0505 \mathrm{~m} / \mathrm{s}$} \\
\hline & & & \multirow{2}{*}{$\begin{array}{l}\begin{array}{l}\text { Triangular } \\
\text { Relationship }\end{array} \\
\text { Film Thickness }\end{array}$} & \multicolumn{3}{|c|}{ Liquid Entrainment Correlations } \\
\hline & & & & $\begin{array}{l}\text { Pan \& Hanratty } \\
(2002 b)\end{array}$ & $\begin{array}{l}\text { Paleev \& Fillippovich } \\
(1966)\end{array}$ & Mantilla (2008) \\
\hline 0.01805 & 0.22851 & 0.18109 & 0.25404 & $8.84044 \mathrm{E}-06$ & 0.011614078 & 0.000673121 \\
\hline 0.01678 & 0.21238 & 0.17616 & 0.22012 & $1.2937 \mathrm{E}-05$ & 0.04033245 & 0.000691296 \\
\hline 0.01608 & 0.20338 & 0.17360 & 0.20787 & $1.56074 \mathrm{E}-05$ & 0.054660605 & 0.000697074 \\
\hline 0.01484 & 0.18775 & 0.16811 & 0.17948 & $1.974 \mathrm{E}-05$ & 0.072768205 & 0.000694863 \\
\hline 0.01454 & 0.18390 & 0.16503 & 0.16571 & $2.55332 \mathrm{E}-05$ & 0.092833339 & 0.000717282 \\
\hline 0.01418 & 0.17928 & 0.16286 & 0.15528 & $3.2343 \mathrm{E}-05$ & 0.111487851 & 0.000735483 \\
\hline 0.01355 & 0.17137 & 0.15922 & 0.14204 & 4.15304E-05 & 0.131456057 & 0.000748038 \\
\hline 0.01306 & 0.16514 & 0.15623 & 0.13006 & 5.15951E-05 & 0.148994146 & 0.000759461 \\
\hline 0.01278 & 0.16160 & 0.15508 & 0.12558 & $5.65125 \mathrm{E}-05$ & 0.156410786 & 0.000762028 \\
\hline 0.01227 & 0.15502 & 0.15137 & 0.11301 & 7.42342E-05 & 0.178847765 & 0.000777846 \\
\hline 0.01203 & 0.15205 & 0.15005 & 0.10861 & $8.71451 \mathrm{E}-05$ & 0.192192144 & 0.000788953 \\
\hline 0.01204 & 0.15216 & 0.14985 & 0.10799 & 0.000120391 & 0.219445402 & 0.000827504 \\
\hline 0.01224 & 0.15471 & 0.15030 & 0.10767 & 0.00018716 & 0.257454679 & 0.000856896 \\
\hline
\end{tabular}


Table 3. Experimental Results for $V s l=0.0714 m / s$ with Liquid Entrainment Correlations.

\begin{tabular}{lllllll}
\hline & \multicolumn{5}{c}{ Vsl= 0.0714m/s } \\
\hline & $\begin{array}{l}\text { Rings+Liq } \\
\text { Entrain }\end{array}$ & Probes (Bottom) & $\begin{array}{l}\text { Triangular } \\
\text { Relationship }\end{array}$ & \multicolumn{2}{l}{ Liquid Entrainment Correlations } \\
\hline $\begin{array}{l}\text { HL+Liq } \\
\text { Entrain }\end{array}$ & $\begin{array}{l}\text { Film Thickness } \\
(\mathbf{m m})\end{array}$ & $\begin{array}{l}\text { Film Thickness } \\
(\mathbf{m m})\end{array}$ & Film Thickness & $\begin{array}{l}\text { Pan \& Hanratty } \\
\mathbf{( 2 0 0 2 b )}\end{array}$ & $\begin{array}{l}\text { Paleev \& Fillippovich } \\
(\mathbf{1 9 6 6 )})\end{array}$ & Mantilla (2008) \\
\hline 0.02251 & 0.28528 & 0.20714 & 0.26959 & $8.81788 \mathrm{E}-06$ & 0.065940703 & 0.000664107 \\
0.02115 & 0.26788 & 0.20362 & 0.23915 & $1.25164 \mathrm{E}-05$ & 0.091332006 & 0.000681619 \\
0.01957 & 0.24780 & 0.19932 & 0.20482 & $1.71117 \mathrm{E}-05$ & 0.114274913 & 0.000688195 \\
0.01885 & 0.23868 & 0.19726 & 0.18937 & $2.1732 \mathrm{E}-05$ & 0.131996775 & 0.00070105 \\
0.01758 & 0.22253 & 0.19364 & 0.17408 & $2.56301 \mathrm{E}-05$ & 0.144327877 & 0.0006918 \\
0.01649 & 0.20864 & 0.19096 & 0.16061 & $3.63006 \mathrm{E}-05$ & 0.170623647 & 0.000704438 \\
0.01538 & 0.19452 & 0.18763 & 0.14862 & $4.63026 \mathrm{E}-05$ & 0.189247269 & 0.000701884 \\
0.01429 & 0.18076 & 0.18392 & 0.14042 & $5.73847 \mathrm{E}-05$ & 0.20583986 & 0.000695099 \\
0.01373 & 0.17362 & 0.18148 & 0.13479 & $6.81562 \mathrm{E}-05$ & 0.219262538 & 0.000696921 \\
0.01329 & 0.16800 & 0.17929 & 0.13118 & $8.07987 \mathrm{E}-05$ & 0.232649212 & 0.000701581 \\
0.01353 & 0.17103 & 0.18046 & 0.13294 & $9.44192 \mathrm{E}-05$ & 0.245003222 & 0.000725321 \\
0.01334 & 0.16865 & 0.17936 & 0.13176 & 0.000128741 & 0.269881119 & 0.000752184 \\
0.01368 & 0.17302 & 0.18063 & 0.13403 & 0.000201225 & 0.3064282 & 0.000812784 \\
\hline
\end{tabular}

Table 4. Experimental Results for Vsl=0.0903m/s with Liquid Entrainment Correlations.

\begin{tabular}{lllllll}
\hline & \multicolumn{5}{c}{ Vsl= 0.0903m/s } \\
\hline & $\begin{array}{l}\text { Rings+Liq } \\
\text { Entrain }\end{array}$ & Probes (Bottom) & $\begin{array}{l}\text { Triangular } \\
\text { Relationship }\end{array}$ & \multicolumn{2}{l}{ Liquid Entrainment Correlations } \\
\hline $\begin{array}{l}\text { HL+Liq } \\
\text { Entrain }\end{array}$ & $\begin{array}{l}\text { Film Thickness } \\
(\mathbf{m m})\end{array}$ & $\begin{array}{l}\text { Film Thickness } \\
(\mathbf{m m})\end{array}$ & Film Thickness & $\begin{array}{l}\text { Pan \& Hanratty } \\
\text { (2002b) }\end{array}$ & $\begin{array}{l}\text { Paleev \& Fillippovich } \\
(\mathbf{1 9 6 6 )})\end{array}$ & Mantilla (2008) \\
\hline 0.02756 & 0.34968 & 0.21259 & 0.24284 & $1.05367 \mathrm{E}-05$ & 0.120875441 & 0.000596097 \\
0.02641 & 0.33496 & 0.21056 & 0.22368 & $1.30848 \mathrm{E}-05$ & 0.136251259 & 0.000603718 \\
0.02514 & 0.31879 & 0.20868 & 0.20703 & $1.7704 \mathrm{E}-05$ & 0.157889019 & 0.000616625 \\
0.02356 & 0.29862 & 0.20673 & 0.19245 & $2.44689 \mathrm{E}-05$ & 0.181291954 & 0.000624689 \\
0.02238 & 0.28360 & 0.20526 & 0.18504 & $3.07099 \mathrm{E}-05$ & 0.197881545 & 0.000626701 \\
0.02102 & 0.26620 & 0.20264 & 0.17463 & $3.76685 \mathrm{E}-05$ & 0.212915489 & 0.000622168 \\
0.01944 & 0.24619 & 0.19922 & 0.16446 & $4.71418 \mathrm{E}-05$ & 0.229566427 & 0.000612997 \\
0.01849 & 0.23400 & 0.19676 & 0.15629 & $5.72604 \mathrm{E}-05$ & 0.24412102 & 0.000611549 \\
0.01780 & 0.22528 & 0.19484 & 0.15165 & $6.8818 \mathrm{E}-05$ & 0.257991535 & 0.000613694 \\
0.01764 & 0.22328 & 0.19431 & 0.15162 & $8.12756 \mathrm{E}-05$ & 0.270638358 & 0.000625869 \\
0.01784 & 0.22574 & 0.19491 & 0.15210 & $9.66806 \mathrm{E}-05$ & 0.283930857 & 0.000647159 \\
0.01788 & 0.22625 & 0.19488 & 0.15145 & 0.000137152 & 0.311032887 & 0.00068202 \\
0.01815 & 0.22975 & 0.19558 & 0.15450 & 0.000205867 & 0.343085224 & 0.000728772 \\
\hline
\end{tabular}

Table 5. Experimental Results for Vsl=0.1355m/s with Liquid Entrainment Correlations.

\begin{tabular}{|c|c|c|c|c|c|c|}
\hline \multirow[b]{3}{*}{$\begin{array}{l}\text { HL+Liq } \\
\text { Entrain }\end{array}$} & \multirow{3}{*}{$\begin{array}{l}\text { Rings+Liq } \\
\text { Entrain } \\
\text { Film Thickness } \\
(\mathrm{mm})\end{array}$} & \multirow{3}{*}{$\begin{array}{l}\text { Probes (Bottom) } \\
\begin{array}{l}\text { Film Thickness } \\
(\mathrm{mm})\end{array} \\
\end{array}$} & \multicolumn{4}{|l|}{$V s l=0.1355 \mathrm{~m} / \mathrm{s}$} \\
\hline & & & \multirow{2}{*}{$\begin{array}{l}\begin{array}{l}\text { Triangular } \\
\text { Relationship }\end{array} \\
\text { Film Thickness }\end{array}$} & \multicolumn{3}{|c|}{ Liquid Entrainment Correlations } \\
\hline & & & & $\begin{array}{l}\text { Pan \& Hanratty } \\
(2002 b)\end{array}$ & $\begin{array}{l}\text { Paleev \& Fillippovich } \\
\text { (1966) }\end{array}$ & Mantilla (2008) \\
\hline 0.03457 & 0.43947 & 0.21626 & 0.22367 & $1.01927 \mathrm{E}-05$ & 0.195314219 & 0.000429514 \\
\hline 0.03119 & 0.39604 & 0.21335 & 0.20353 & $1.50056 \mathrm{E}-05$ & 0.221870684 & 0.000428117 \\
\hline 0.03015 & 0.38281 & 0.21244 & 0.19722 & $1.95658 \mathrm{E}-05$ & 0.240229469 & 0.000437098 \\
\hline 0.02934 & 0.37249 & 0.21175 & 0.19142 & $2.64058 \mathrm{E}-05$ & 0.26111893 & 0.000449972 \\
\hline 0.02872 & 0.36456 & 0.21120 & 0.19045 & $3.13169 \mathrm{E}-05$ & 0.273078558 & 0.000455276 \\
\hline 0.02703 & 0.34287 & 0.20923 & 0.18198 & $4.05152 \mathrm{E}-05$ & 0.291243541 & 0.000453727 \\
\hline 0.02545 & 0.32271 & 0.20695 & 0.17506 & $5.03723 \mathrm{E}-05$ & 0.306713013 & 0.000449773 \\
\hline 0.02465 & 0.31253 & 0.20565 & 0.16948 & 5.93779E-05 & 0.318466965 & 0.000450753 \\
\hline 0.02836 & 0.35985 & 0.20928 & 0.17279 & $7.74809 \mathrm{E}-05$ & 0.337617407 & 0.000519825 \\
\hline 0.02884 & 0.36600 & 0.20978 & 0.17678 & $9.11854 \mathrm{E}-05$ & 0.349423641 & 0.000539053 \\
\hline 0.02871 & 0.36434 & 0.20952 & 0.17548 & 0.0001061 & 0.360466299 & 0.000549969 \\
\hline 0.02846 & 0.36115 & 0.20916 & 0.17502 & 0.000146966 & 0.384427856 & 0.000573253 \\
\hline 0.02889 & 0.36665 & 0.20963 & 0.17732 & 0.000220828 & 0.414805523 & 0.000613875 \\
\hline
\end{tabular}


Table 6. Experimental Results for Vsl $=0.1851 \mathrm{~m} / \mathrm{s}$ with Liquid Entrainment Correlations.

\begin{tabular}{lllllll}
\hline & \multicolumn{5}{l}{ Vsl= 0.1851 m/s } \\
\hline & Rings+Liq Entrain & Probes (Bottom) & Triangular Relationship & \multicolumn{2}{l}{ Liquid Entrainment Correlations } \\
\hline $\begin{array}{l}\text { HL+Liq } \\
\text { Entrain }\end{array}$ & \multirow{2}{*}{ Film Thickness (mm) } & $\begin{array}{l}\text { Film Thickness } \\
(\mathbf{m m})\end{array}$ & Film Thickness & $\begin{array}{l}\text { Pan \& Hanratty } \\
\mathbf{( 2 0 0 2 b )}\end{array}$ & $\begin{array}{l}\text { Paleev \& Fillippovich } \\
(\mathbf{1 9 6 6})\end{array}$ & $\begin{array}{l}\text { Mantilla } \\
(\mathbf{2 0 0 8})\end{array}$ \\
\hline 0.04085 & 0.52007 & 0.21969 & 0.19066 & $1.09668 \mathrm{E}-05$ & 0.26412317 & 0.000332846 \\
0.03930 & 0.50014 & 0.21871 & 0.17970 & $1.55495 \mathrm{E}-05$ & 0.287628357 & 0.000343469 \\
0.03833 & 0.48762 & 0.21831 & 0.17710 & $2.09501 \mathrm{E}-05$ & 0.307812108 & 0.000354511 \\
0.03651 & 0.46431 & 0.21690 & 0.17153 & $2.73002 \mathrm{E}-05$ & 0.325834465 & 0.000357693 \\
0.03551 & 0.45151 & 0.21630 & 0.16777 & $3.4044 \mathrm{E}-05$ & 0.340937429 & 0.000362948 \\
0.03484 & 0.44289 & 0.21579 & 0.16848 & $4.25787 \mathrm{E}-05$ & 0.356316405 & 0.000370816 \\
0.03416 & 0.43420 & 0.21528 & 0.16794 & $5.40796 \mathrm{E}-05$ & 0.372842703 & 0.000379482 \\
0.03419 & 0.43460 & 0.21524 & 0.17067 & $6.80068 \mathrm{E}-05$ & 0.388772832 & 0.000393733 \\
0.03462 & 0.44002 & 0.21534 & 0.16986 & $8.08113 \mathrm{E}-05$ & 0.400828043 & 0.000408152 \\
0.03440 & 0.43725 & 0.21522 & 0.16813 & $9.66061 \mathrm{E}-05$ & 0.413363336 & 0.000417459 \\
0.03466 & 0.44054 & 0.21516 & 0.16832 & 0.000112782 & 0.424284989 & 0.000430029 \\
0.03487 & 0.44321 & 0.21555 & 0.17075 & 0.00015998 & 0.449134676 & 0.000454396 \\
0.03451 & 0.43868 & 0.21503 & 0.16743 & 0.000239564 & 0.478183455 & 0.000478042 \\
\hline
\end{tabular}

Film Thickness using Conductivity Ring Sensors.

Figure 5 is a graph of film thickness against superficial gas velocity from conductivity ring sensors. It shows that film thickness decreases with increase in superficial gas velocity as observed in Figure 4 . The $\mathrm{Vsl}=0.1355 \mathrm{~m} / \mathrm{s}$ had an upward projection which was because of increase in Vsl in the flow loop, hence was removed. The error bar plot on average $\mathrm{Vsl}=0.1851 \mathrm{~m} / \mathrm{s}$ was the error propagation of $\pm 0.0844 \mathrm{~mm}$ of the film thickness which shows the level of accuracy of the measured values.

Film Thickness using Triangular Relationship

It is a unique method for determining liquid film thickness in annular flow in pipes. Triangular relationship recognizes three variables that are dependent on one another: pressure gradient, liquid film rate and liquid film thickness. It is a correlation that is based on pressure gradient and liquid film flow rate as a function of film thickness. The liquid film flow rate, could be obtained by measuring the liquid film thickness and pressure gradient on a straight pipe segment, [6, 7] clearly simplified it for flow in round tubes with assumptions that gravitational and acceleration effects are ignored. Therefore, all flow in pipes, and flows in the film including shear stress equals that of wall shear stress, other assumptions of the correlation are: all liquid flow in the pipe do not flow in the film, liquid droplets and circumferential liquid flows across pipes in annular flow. Triangular relationship for film thickness, is often used for upward flow in pipes with equation as

$$
\dot{M}=f\left(\delta \frac{d p}{d z}\right)
$$

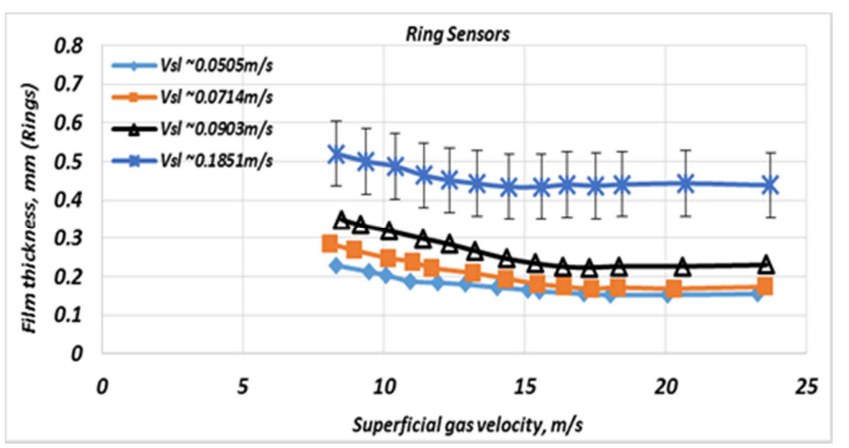

Figure 5. Film thickness from ring sensor against superficial gas velocity.
From the pressure gradients and liquid flow rates from the experiments, the liquid film thickness using triangular relationship method was presented in figure 6 . Figure 6 , is the plot of triangular relationship (liquid film thickness) against superficial gas velocity. Triangular relationship from the graph, has shown that film thickness decreases with increase in superficial gas velocity. Again, from the same Figure 6, it was presented that the higher the superficial liquid velocity, the higher the film thickness, hence the average Vsl of $0.1851 \mathrm{~m} / \mathrm{s}$, represented the highest film thickness in the analyses.

One observation from the graph was a uniform decline among all the superficial liquid velocity. The decline in the liquid film thickness was observed with less changes as the average superficial gas velocity increases from $16.2262 \mathrm{~m} / \mathrm{s}$ to $23.4575 \mathrm{~m} / \mathrm{s}$. The reason is because the entrained liquid droplets overtime, will become larger due to high gas velocity that results to more break-up and lifting of these liquid droplets as superficial gas velocity increases in horizontal pipe. These liquid droplets will descend back to the bottom of the pipes through the walls of the pipes, as gravity impacts on the droplets. This phenomenon, presented the liquid film thickness plots to appear nearly as a straight line in Figure 6. The convergence on average $\mathrm{Vsg}=8.2699 \mathrm{~m} / \mathrm{s}$ to $12.0675 \mathrm{~m} / \mathrm{s}$ in Figure 6 is because, triangular relationship presented liquid film thickness, to be decreasing with increase in superficial liquid velocity, and increasing with decrease in superficial liquid velocity. This is because triangular relationship is for annular flow in vertical pipes and not horizontal flow in pipes.

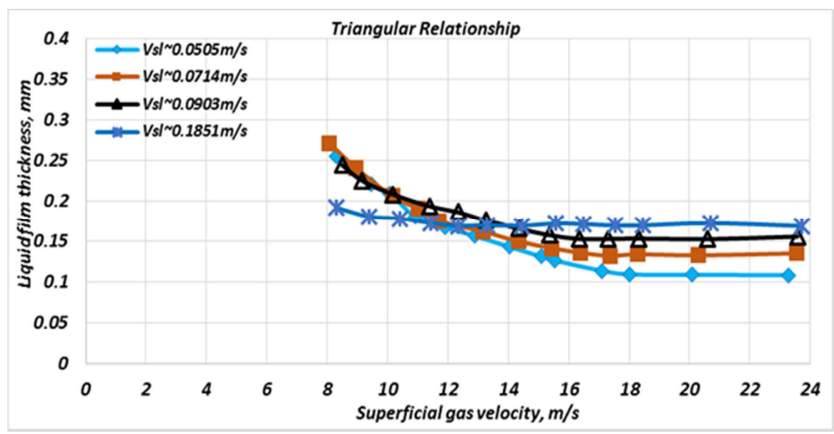

Figure 6. Film thickness Vs Vsg using Triangular Relationship. 
Comparing liquid film thickness from different methods

The annular flow liquid film thickness results from the experiments, were determined using the following methods:

1. Conductivity Ring Sensors,

2. Conductance Probe Sensors and,

3. Triangular Relationship.

The results of the three methods, were plotted in Figures 7 and 8 with $\mathrm{Vsl}=0.0505 \mathrm{~m} / \mathrm{s}$ and $0.0714 \mathrm{~m} / \mathrm{s}$ respectively, while the performance plots were presented in Figures 9 and 10, and the detailed results analysis in Tables 2-6.

The graph of Figure of 7 presented a similar trend among the three methods, except the little variance from the graphs of the probes. However, conductivity ring sensors and triangular relationship plots for liquid film thickness, represents the true scenario where the liquid film thickness flows, circumferentially across entire walls of the pipes. Meanwhile, the probes only accounted for the liquid film thickness at the bottom of the pipe, hence the difference seen in Figure 7. Again, the little difference between the conductivity ring sensors and the triangular relationship could also be attributed to uncertainties from bench calibration, which was used in determining film thickness for the conductivity ring sensors' method.

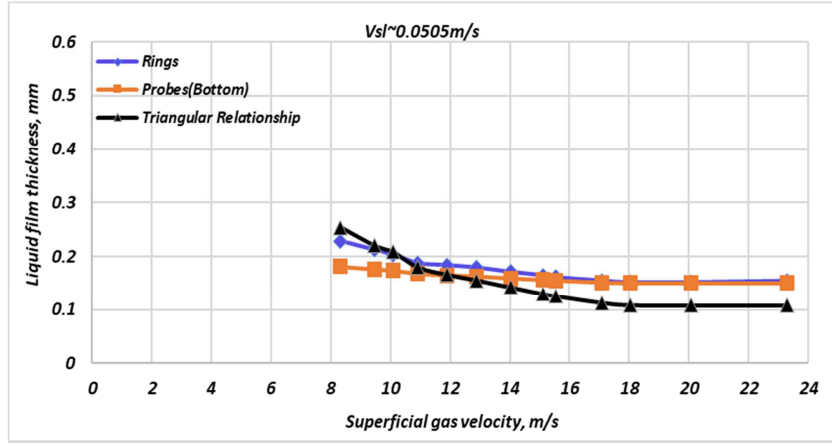

Figure 7. Comparing film thickness from three methods $(V s l \sim 0.0505 \mathrm{~m} / \mathrm{s}$ )

From figure 8 , the film thickness from conductivity rings sensors and the triangular relationship showed similar trend while the plot from probes was a bit different from that of average superficial gas velocities of $8.2699 \mathrm{~m} / \mathrm{s}$ to $14.2883 \mathrm{~m} / \mathrm{s}$. Again, the probe represents, only the film thickness at the bottom of the pipe which is the difference in the plots.

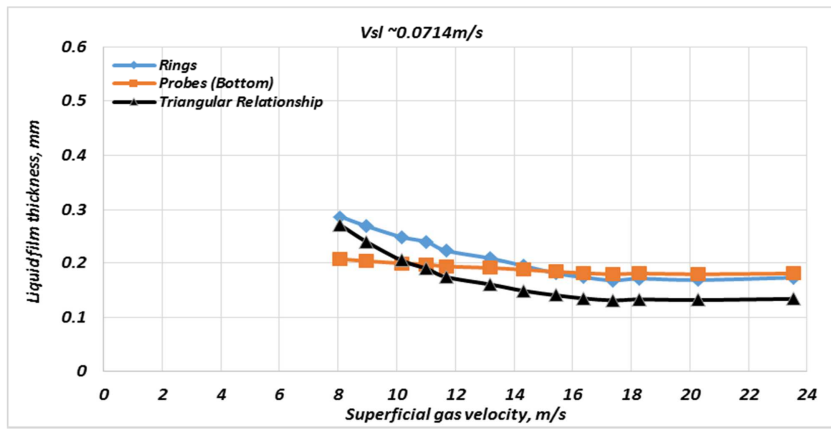

Figure 8. Comparing film thickness from three methods $(V s l \sim 0.0714 \mathrm{~m} / \mathrm{s})$.

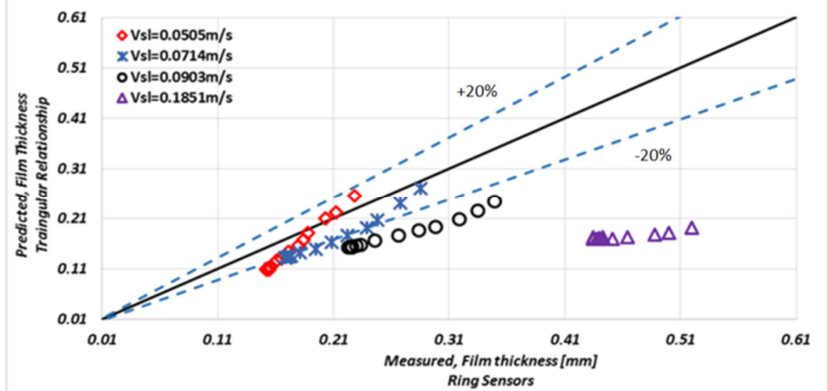

Figure 9. Plot of Predicted against Measured Liquid Film Thickness from Ring Sensors.

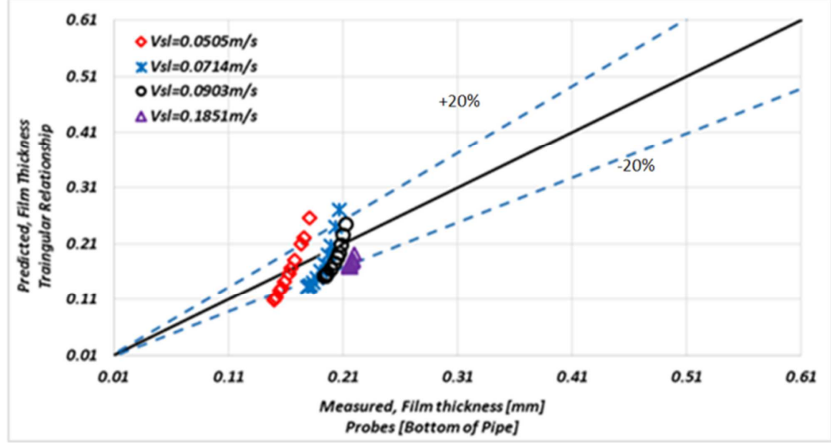

Figure 10. Plot of Predicted against Measured Liquid Film Thickness from Probes.

The graphs of Figures 9 and 10 are the predicted liquid film thickness from triangular relationship against the measured film thickness from conductivity ring sensors and probes. From Figure 9, the liquid film thickness from triangular relationship under-predicted liquid film thickness, when compared with liquid film thickness from conductivity ring sensors. The plot of average $\mathrm{Vsl}=0.1851 \mathrm{~m} / \mathrm{s}$ was completely off, showing a wide difference while plots of $\mathrm{Vsl}=0.0505 \mathrm{~m} / \mathrm{s}$ and $\mathrm{Vsl}=0.0714 \mathrm{~m} / \mathrm{s}$, preferably matched. For probes, the predicted triangular relationship liquid film thickness matched better with the measured liquid film thickness from probes in all the superficial liquid velocities. This is to illustrate that probes detects liquid film thickness better than conductivity ring sensors in annular flow as seen Figure 8. The reason is because of the impact of high superficial gas velocity on conductivity ring sensors which will be a green area for future research in annular flow in pipes.

\section{Conclusion}

To understand the dynamics of annular flow in pipes, liquid film thickness was analyzed. Liquid film thickness in all the flow matrix in this study were observed decreasing with increase in gas velocity while increasing with increase in liquid velocity. The decreasing tendency with gas velocity was because of liquid entrainment. The liquid entrainments, were accounted for using [17] correlation. The correlation gave the more realistic results among other correlations compared from the experimental data. This was further proven by [10] analysis on liquid entrainment correlations for horizontal pipes where [17] was presented as a correlation 
that preferably, predicts liquid entrainment.

\section{Acknowledgements}

The author would like to express his gratitude to Prof Gioia Falcone, Head of Oil and Gas Engineering Centre, Cranfield University, Bedfordshire, UK and Dr Lao Liyun for their support and for making the required instruments available for this work. Also, to the PSE Lab Manager, Mr Stan Collins. And finally, to say thank you to TETFUND for the sponsorship and Prof J. A. Ajienka, for his mentorship.

\section{References}

[1] Anderson, R. J and Russell, T. W. F., (1970) "Circumferential Variation of Interchange in Horizontal Annular Two-Phase Flow", Ind. Engrg. Chem. Fundam. 9, 340-344.

[2] Butterworth, D. (1972) "Air-Water Annular Flow in a Horizontal Tube", Prog. Heat Mass Transfer, 6, 235-251.

[3] Chien, S and Ibele, W., (1964) "Pressure Drop and Liquid Film Thickness of Two-Phase Annular and Annular-Mist Flows", ASME J. Heat Transfer, 86, pp. 80-86.

[4] Chao, T, Dong, F and Shi, Y (2011) "Data Fusion for Measurement of Water Holdup in Horizontal Pipes by Conductivity Rings" IEEE, 978-1.

[5] Dallman, J. C, Jones, B. G and Hanratty, T.J (1979) "Interpretation of Entrainment Measurements in Annular GasLiquid Flows" Int. J. Heat and Mass Transfer, Vol. 2, pp. 681693, Hemisphere, Washington, D.C.

[6] Falcone, G, Hewitt, G.F and Richardson, S.M (2003) "ANUMET: A Novel Wet Gas Flowmeter" SPE Annual Technical Conference and Exhibition, Denver, Colorado, U.S.A. 5-8October.

[7] Hewitt, G.F and Hall-Taylor, N.S (1970) “Annular Two-Phase Flow" Pergamon Press.

[8] Kesana, N.R., Throneberry, J.M., Mclaury, B.S., Shirazi, S.A and Rybicki, E.F, (2012) "Effect of Particle Size and Viscosity on Erosion in Annular and Slug Flow" Proceedings of the ASME 2012 International Mechanical Engineering Congress \& Exposition IMECE2012, November 9-15, 2012, Houston, Texas, USA.

[9] Lin, P. Y (1985) "Flow Regime Transitions in Horizontal GasLiquid Flow", PhD. Thesis, Univ. of Illinois, Urbana.

[10] Magrini, K. L, Sarica, C, Al-Sarkhi, A and Zhang, H, Q (2012) "Liquid Entrainment in Annular Gas/Liquid Flow in Inclined Pipes" accepted at SPE Annual Technical Conference and Exhibition, Florence, Italy, 19-22 September 2010, Published on SPE Journal, June, 2012.
[11] Mantilla, I. (2008) "Mechanistic Modelling of Liquid Entrainment in Gas in Horizontal Pipes" PhD thesis, University of Tulsa, Tulsa, Oklahoma.

[12] Mantilla, I., Gomez, L., Mohan, R., Shoham, O., Kouba, G and Roberts, R. (2009) "Modelling of Liquid Entrainment in Gas in Horizontal Pipes, Proc., ASME 2009 Fluids Engineering Division Summer Meeting, Colorado, USA, Vol. 1, No FEDSM2009-78459, pp. 979-1007.

[13] McManus, H.N. Jr. "Local Liquid Distribution and Pressure Drops in Annular Two-Phase Flow, " paper 61-HYD-20 presented at the 1961 ASME Hydraulic Conference, Montreal, Canada.

[14] Osokogwu, U (2018) "Evaluation of Wave Frequency Correlations in Annular Flow in Horizontal Pipe" Journal of Scientific and Engineering Research, 5 (7), pp. 75-81.

[15] Osokogwu, Uche (2018) "Effects of Velocity on Pressure Gradient, Slip and Interfacial Friction Factor in Annular Flow in Horizontal Pipe" European Journal of Engineering Research and Sciences, Vol, 3, No. 8, August, pp. 5-11.

[16] Paleev, I. I and Filipovich, B. S., (1966) "Phenomena of Liquid Transfer in Two-Phase Dispersed Annular Flow", Int. J. Heat Mass Transfer, 9, 1089.

[17] Pan, L. and Hanratty, T. J (2002) (b) "Correlation of Entrainment for Annular Flow in Horizontal Pipes" Int. $J$. Multiphase Flow, Vol. 28 (3), pp. 385-408.

[18] Pearce, D. L. and Fisher, S. A. (1979) A Theoretical Model for describing Horizontal Annular Flows, In Two-Phase Momentum, Heat and Mass Transfer in Chemical, Process and Energy Engineering Systems, pp. 327-333, Hemisphere/McGraw-Hill, Washington, D.C.

[19] Sergey, V. Alekseenko, Andrey, V. Cherdantsev, Mikhail, V. Cherdantsev, Sergey, V. Isaenkov, Sergey, M. Kharlamov and Dmitriy, M. Markovich (2014) "Formation of Disturbance Waves in Annular Gas-Liquid Flow" Kutateladze Institute of Thermophysics, Novosibirsk, Russia, Novosibirsk State University, Novosibirsk, Russia, $17^{\text {th }}$ International Symposium on Applications of Laser Techniques to Fluid Mechanics, Lisbon, Portugal, 07-10 July, 2014.

[20] Setyawan, A., Indarto and Deendarlianto (2016) "The Effect of the Fluid Properties on the Wave Velocity and Wave Frequency of Gas-Liquid Annular Two-Phase Flow in a Horizontal Pipe" Experimental Thermal and Fluid Science, ELSEVIER, Vol. 71, pp 25-41.

[21] Shedd, T. A., (2001) "Characteristics of the Liquid Film in Horizontal Two-Phase Flow", Thesis for Doctor of Phil. in Mechanical Engineering the University of Illinois at UrbanaChampaign.

[22] Tellas, A. S and Dukler, A. E., (1970) "Statistical Characteristics of Thin, Vertical, Wavy Liquid Films" Ind. Eng. Chem. Fundam., 9 (3), pp. 412-421.

[23] Wicks, M. and Dukler, A. E., (1960) "Entrainment and Pressure Drop in Concurrent Gas-Liquid Flow: Air-Water in Horizontal Flow" AIChE. J, 6, 463. 